\title{
El Hespérides y la aportación de la Armada a la investigación científica
}

\section{Carlos Cordón Scharfhausen}

Arbor CLXXIII, 682 (Octubre 2002), 385-403 pp.

A los lectores de la revista Arbor debe resultarles familiar el contenido de este artículo puesto que el Consejo Superior de Investigaciones Científicas fue pionero y decidido impulsor de la presencia española en la Antártida y de la construcción del buque de investigación oceanográfica «Hespérides».

El capitán de navio Cordón, que fue su comandante durante dos años, resume atinadamente los antecedentes históricos de este empeño y del complejo proceso de adhesión de España al Tratado Antártico hasta llegar a la construcción de este buque de investigación multidisciplinar, de cuyas características y equipamiento científico hace una detallada descripción que resulta del máximo interés para quienes estén relacionados o deseen asomarse a este apasionante campo de la ciencia.

La participación continuada de la Armada desde 1987 en las campañas antárticas queda claramente reflejada a lo largo del artículo, así como las múltiples actividades y trabajos que se realizan a bordo del «Hespérides» en estrecha colaboración con otros organismos nacionales, en una clara y decidida voluntad de presencia y contribución de la Armada a la investigación científica.

\section{Antecedentes}

En octubre de 1988, el Gobierno español tomaba una decisión que sería trascendental para la ciencia española: la decisión de construir 
un buque de investigación oceanográfica para prestar apoyo logístico y operar en la Antártida. Para poder valorar este acontecimiento de importancia capital para la investigación oceanográfica española es necesario comprender la convergencia y sinergia de dos fuerzas en el campo de la ciencia: la voluntad política y ambición científica para formar parte del selecto «club» de naciones del Tratado Antártico, y los anhelos de la comunidad oceanográfica española para disponer de un buque multidisciplinar del nivel adecuado a nuestro potencial y a la importancia que debe tener la Ciencia y la Tecnología Marina (CYTMAR) en un país de condición marítima como España.

\section{De la Investigación Oceanográfica en España}

Durante los años 70 y 80 del siglo pasado, la investigación oceanográfica, al estar enfocada eminentemente a los recursos pesqueros, se centraba en las aguas costeras españolas y del Atlántico, y por tanto estaba liderada por el Instituto Español de Oceanografía (IEO). Los buques de investigación eran en realidad pesqueros transformados, de unos 30 metros de eslora y de reducido desplazamiento, lo que llevaba consigo una gran carencia de equipamiento científico y de capacidad para embarcar científicos y técnicos. Como ejemplos pueden citarse el Cornide de Saavedra perteneciente al IEO o el García del Cid del Consejo Superior de Investigaciones Científicas (CSIC). Naturalmente, la creciente comunidad científica marina española, como es lógico, anhelaba disponer de un buque de investigación oceanográfico multidisciplinar y con un equipamiento científico moderno, al más alto nivel, que permitiese a nuestros investigadores integrarse en la naciente comunidad científica europea, aspirando a ser competitivos en determinados campos de las ciencias del mar. Hasta finales de la década de los 80, el máximo aliciente para cualquier científico español era formar parte de algún equipo de investigación extranjero y tener opción a embarcar en buques oceanográficos de mayor porte y capacidad tecnológica.

\section{De la presencia española en la Antártida}

Conviene resaltar que en 1603 tiene lugar el primer avistamiento de las islas Shetland del Sur por el Almirante Gabriel de Castilla cuando navegaba en persecución de buques holandeses e ingleses con su navío Buena Nueva por el entonces denominado Mar de Castilla (hoy en día Paso Drake o Mar de Hoces). En honor del Almirante toma su nombre una de las dos actuales Bases Antárticas Españolas 
(BAEs), concretamente la situada en Isla Decepción de las Shetland del Sur y que está gestionada por el Ejército de Tierra.

En 1818 tiene lugar la pérdida del navío San Telmo (de ¡75 años!) lleno de soldados españoles enviados hacia Lima para intentar sofocar los movimientos independentistas. Naufragó en la parte norte de Isla Livingston pereciendo los 644 españoles embarcados. En esta isla, en Bahía Sur, se encuentra situada la otra BAE Juan Carlos I (JCI).

En 1957 y 1958 tiene lugar el Año Geofísico Internacional (AGI), centrado en la investigación en la Antártida, y España tiene que renunciar a tomar parte en las investigaciones del AGI debido a las carencias científicas, técnicas y logísticas de aquellos años. En 1958 tiene lugar la creación del SCAR (Scientific Committee on Antarctic Research), organización no gubernamental de carácter científico. El acceso al SCAR de las naciones sólo puede efectuarse por medio de investigaciones científicas relevantes en la Antártida, y demostrando fehacientemente un interés mantenido y sólido.

En 1959 tiene lugar la firma del Tratado Antártico (TA) por los 12 países signatarios originales: Reino Unido, Noruega, Francia, Bélgica, EE.UU., Unión Soviética, Japón, Nueva Zelanda, Australia, Sudáfrica, Argentina y Chile (en cursiva países con reclamaciones territoriales sobre la Antártida). El tratado fijaba que se procedería a su revisión a los 30 años de su firma, es decir en 1989; y también contempla que es interés de toda la humanidad que la Antártida continúe utilizándose siempre exclusivamente para fines pacíficos y que no llegue a ser escenario u objeto de discordia internacional, a la vez que se reconoce la importancia de las contribuciones aportadas al conocimiento científico como resultado de la cooperación internacional (AGI y SCAR).

Aunque España estuvo ausente del AGI y no formaba parte del SCAR, algunos científicos españoles sí formaron parte de algunas expediciones e investigaciones extranjeras (Luis Aldaz, Pepe Ballester, Josefina Castellví, ..) e hicieron una auténtica labor de «apostolado», haciendo ver la necesidad de que España llegase a ser un miembro activo del selecto «club» de naciones que formaban parte del TA. Por ello, no es de extrañar que en 1982 España solicitase su ingreso como miembro adherente del Tratado Antártico, siendo admitida con fecha 31 de marzo de ese mismo año. En realidad fue tan solo la expresión formal por parte del Gobierno español de demostrar su interés por las actividades científicas que se desarrollaban en la Antártida. A partir de dicha fecha los acontecimientos se precipitan. Así, en 1983 tiene lugar la que iba a ser la primera campaña científica española en la Antártida y que quedó en una aventura, la de la goleta Idus de Marzo, 
que contó con el apoyo inicial del IEO; pero una serie de retrasos y averías hicieron postergar su llegada a la Antártida a finales de marzo, ya acabado el verano austral. Sin embargo, las bellísimas imágenes grabadas tuvieron una gran importancia en la divulgación de la existencia e importancia de la Antártida.

En 1984, y con motivo de la II Semana de Estudios del Mar (Cartagena), tiene lugar la presentación de un proyecto de buque oceanográfico polar español (AH-41) por la Empresa Nacional Bazán (actual Izar), que en diciembre de ese mismo año fue sometido a la consideración del Ministerio de Asuntos Exteriores (MAE) como Propuesta de Estudio de Previabilidad. Al año siguiente, en la III Semana de Estudios del Mar, la EN Bazán expone un documento denominado «Definición de los requerimientos básicos del Buque de Investigación Oceanográfica $B I O$ y proyecto de contrato», que más tarde es presentado por la citada empresa, consiguiendo la asignación de un crédito por parte del MAE.

En 1986 tiene lugar la expedición científica a la Antártida en los pesqueros Nuevo Alcocero y Pescapuerta $I V$ organizada por el IEO, y enfocada principalmente a evaluar los potenciales recursos pesqueros.

En 1987 se consigna una partida presupuestaria en el entonces Ministerio de Educación y Ciencia (MEC) para la construcción de un Buque de Investigación Oceanográfica $B I O$ con capacidad subpolar (el crédito se consignó como del CSIC). Ese mismo año tiene lugar la auténtica primera campaña científica antártica española auspiciada por el Real Observatorio de la Armada (ROA) en el buque chileno alquilado Río Baker, con objeto de prestar apoyo e iniciar las primeras actividades científicas y levantamientos hidrográficos previos a la instalación de la primera base española en la Antártida.

El 6 de enero de 1988 tiene lugar, en Isla Livingston, la apertura de la BAE Juan Carlos I, formada por unos contenedores finlandeses y un módulo de laboratorios embarcado en Vigo en el buque polaco alquilado Garnulszewsky, siendo los costes financiados por el MAE, quien transfiere la BAE al CSIC para su gestión operativa.

A la vista de estas actividades, el 21 de septiembre de 1988, España es admitida como miembro consultivo, de pleno derecho, con voz $y$ voto del Tratado Antártico. Este hecho conlleva asumir las responsabilidades del Art. IX.2 del TA que dice extractadamente: «tendrá derecho ... mientras dicha Parte Contratante demuestre su interés en la Antártida mediante la realización en ella de investigaciones científicas importantes, como el establecimiento de una estación científica o el envío de una expedición científica.» Para ello es necesario la creación de una comunidad considerable con medios y experiencia en el campo 
El «Hésperides» y la aportación de la Armada...

operativo-logístico, técnico y científico. Hay que indicar, desde el principio, que operar en la Antártida es difícil y costoso, siendo necesaria la coordinación y cooperación internacional, que además es un mandato del TA. También conviene resaltar que hoy en día tan sólo hay 27 países con «status» de miembro consultivo, de un total de 45 que están adheridos al TA.

Volviendo al importante año de 1988, en diciembre tiene lugar la I Expedición a la Antártida en el Remolcador de la Armada Las Palmas y la apertura del -entonces denominado así- «Refugio» del Ejército de Tierra Gabriel de Castilla en Isla Decepción. En esta campaña y las dos siguientes, también realizadas por el buque Las Palmas, continúan efectuándose trabajos topográficos, geológicos y geofísicos, así como el levantamiento hidrográfico de las primeras cartas náuticas de la zona (Bahías Sur, Walker y Falsa), incluida la del bajo de isla Answer, donde recientemente había naufragado el buque argentino Bahía Paraiso.

En 1990tiene lugar la botadura del BIO (todavía no tenía asignado un nombre y se especulaba con Mar Antártico), siendo su madrina S.M. la Reina Doña Sofía. Gracias a estas iniciativas, que demostraban el interés español en la Antártida y los méritos científicos de las primeras campañas antárticas, ese mismo año de 1990 España ingresa en el SCAR.

En abril de 1991 finaliza la III Campaña Antártica del Las Palmas $\mathrm{y}$, un mes más tarde, tiene lugar la entrega del BIO Hespérides a la Armada. El año finaliza con un importante hito y el éxito de nuestra diplomacia con la firma del "Protocolo de Madrid» sobre protección del medio ambiente en la Antártida y sus ecosistemas asociados. España queda así vinculada con la Ciencia y con la Antártida. Ese mismo mes de diciembre comienza la I Campaña Antártica 91/92 del Hespérides, volviendo el Las Palmas a sus cometidos de remolcador de altura de la Armada. Es importante reseñar que en 1999 entró en vigor el «Protocolo de Madrid», por lo que todas las actividades científicas y logísticas deben ajustarse a su estricta normativa para conseguir la protección del medio ambiente antártico y sus ecosistemas asociados al sur del paralelo $60^{\circ}$ del hemisferio austral.

El aumento de los requerimientos de apoyo logístico a nuestras BAEs, con la ampliación y aumento de su capacidades, el apoyo logístico prestado a la Base Antártica Búlgara (BAB) San Clemente de Orhida -en razón de su vecindad a nuestra BAE JCI en Bahía Sur-, así como la necesidad de dedicar más tiempo operativo del Hespérides a las campañas científicas oceanográficas antárticas, obliga a tomar la decisión de incrementar la capacidad de apoyo logístico, y así, el 1 
de diciembre de 2000 se inicia la apertura de las BAEs y de la BAB mediante dos buques de la Armada Española: el Hespérides en su X Campaña Antártica, y la vuelta a la Antártida del Las Palmas en lo que sería su IV Campaña Antártica. Actualmente, ambos buques de la Armada están realizando sus campañas antárticas 2001/2002, las números XI y $\mathrm{V}$ respectivamente.

En julio de 2001 se nombró un embajador español permanente para el TA. Para comprender la importancia que ha tomado la participación española, conviene destacar que en el año 2004 tendrá lugar una Reunión Consultiva del TA en España.

El buque de apoyo logístico y de investigación oceanográfica polar de la Armada Hespérides (A-33)

El Buque de Investigación Oceanográfica BIO Hespérides fue construido en la factoría de Cartagena de la EN Bazán con la partida presupuestaria aprobada el 24 de diciembre de 1987 dentro del entonces MEC. El Consejo de Ministros (21 junio 1988) autorizó al CSIC a «disponer» la construcción de un buque oceanográfico con capacidad antártica, dentro de sus créditos de inversión aprobados, y al Ministerio de Defensa a «contratar» la construcción del citado buque, correspondiéndole la dirección e inspección de la obra. Finalizada la construcción, el buque quedaría integrado en el Ministerio de Defensa, para lo cual sería dado de alta en la Lista Oficial de Buques de la Armada, quien proporcionaría su dotación. En el citado Consejo de Ministros se acordaba también la constitución de un órgano interministerial de planificación de campañas, al que serían sometidas para su aprobación todas las propuestas de campañas a realizar por el buque.

El Hespérides fue entregado a la Armada el 16 de mayo de 1991. En el momento de redactar estas líneas ha desarrollado con éxito más de 75 campañas científicas. Nunca ha faltado a su cita anual con la Antártida en los veranos australes (su actual campaña antártica 2001/2002 es la XI). El buque ha realizado un total de más de 2.500 días de mar (el máximo anual fue de 263 días en 1999), siendo el primer barco español en atravesar el Círculo Polar Antártico (febrero de 1993). Son cifras que impresionan, porque detrás de ellas está la labor callada y cotidiana de las distintas dotaciones de la Armada que han ido relevándose desde ese ya lejano mes de marzo de 1991 en que efectuó su primera salida a la mar.

Estamos pues ante un buque excepcional en el más amplio sentido de la palabra. Por una parte, es el único buque español con capacidad 
El «Hésperides» y la aportación de la Armada...

polar (diseñado específicamente para operar en la zona antártica durante el verano austral hasta los $65^{\circ}$ de latitud sur, y cumplir con los compromisos asumidos por España como miembro consultivo del TA desde 1988 -capacidad de prestar apoyo logístico y de investigación oceanográfica en la Antártida-); y por otra, posee un equipamiento científico multidisciplinar extraordinario de geología y geofísica marina, hidrografía, oceanografía física y química, y de biología marina, sin parangón en España; y muy especialmente en lo que se refiere a su equipamiento de ecosondas (dos multihaz, biológica, paramétrica para sedimentos, y monohaz de precisión) y a su equipamiento para campañas de sísmica multicanal de reflexión, con un conjunto hidrofónico remolcado de 96 canales y $2,5 \mathrm{~km}$ de longitud que le permite investigar la estructura de la corteza terrestre hasta 8 kilómetros de profundidad. Además, por su eslora, autonomía y tonelaje, es el único BIO español con capacidad oceánica real (lo que se denomina buque azul),que le permite operar sin ningún tipo de apoyo en cualquier mar u océano del globo (actualmente tan sólo le falta navegar por el Índico y por el océano Glacial Ártico). Con ser tan singular en todo lo anteriormente apuntado, quizá su aspecto más relevante sea el de ser el único buque nacional de investigación en ciencias marinas abierto a la participación de cualquier grupo científico español, o de la Unión Europea; participación que se hace en base exclusivamente al mérito científico del proyecto presentado y a su adecuación a las prioridades marcadas por el Plan Nacional de Investigación, Desarrollo e Innovación Tecnológica (I+D+I).

Por todo lo expuesto, no es de extrañar que el Hespérides fuese la primera de las grandes instalaciones científicas nacionales, distinción que ahora comparte junto con otras nueve, entre las que cabe destacar el Gran Telescopio de Canarias (GRANTECAN) en la isla de La Palma y las ya citadas Bases Antárticas Españolas (BAEs) Juan Carlos I y Gabriel de Castilla. La actual Comisión de Gestión (científica) del Hespérides está formada por representantes de los Ministerios de Ciencia y Tecnología, Defensa, Medio Ambiente, Educación, y Agricultura, Pesca y Alimentación (llama la atención que no tenga representante el MAE). Por parte de las Instituciones y Organismos Públicos de Investigación (OPIs), esta Comisión cuenta también con representantes de la Armada (el comandante del buque), IEO, Secretaría General de Pesca, CSIC, Consejo de Universidades, y el Instituto Nacional de Meteorología (INM).

\section{Características más relevantes del Hespérides}

Las características más sobresalientes del Hespérides son: 
Eslora máxima: $82,5 \mathrm{mts}$. (un poco alejado de la óptima para aguantar la mar en las grandes extensiones oceánicas, como el Pacífico, pero excelente para maniobrar en el hielo).

Manga: 14,33 mts. (valor que indica una gran superficie disponible en cubierta, gran capacidad de apertura y suficiente protección a la hélice cuando se navega avante abriendo camino entre el hielo marino).

Calado máximo: 5,20 mts. (relativamente escaso para su función como rompehielos, pero que permite el acceso a muchas zonas de poca profundidad con seguridad). Desplazamiento a plena carga: casi 3.000 toneladas (compárese con otros rompehielos, como el Almirante Irízar de la Armada argentina de 15.000 toneladas).

Velocidad máxima: 15 nudos.

Autonomía a su velocidad de crucero de 13 nudos: 12.000 millas. Capacidad para almacenar 4 meses de víveres para 90 personas. Autonomía en combustible para llevar a cabo campañas científicas de hasta 2 meses en operación continuada en la mar (500.000 lts de gasóleo). Diseñado para poder navegar hasta 9 meses fuera de su Arsenal de apoyo (Cartagena), con un ciclo de vida total de 25 años y una modernización prevista a los 8/9 años.

Casco rompehielos para hielo marino de primer año (hasta $40 \mathrm{~cm}$ ) a 5 nudos de velocidad. De su aspecto exterior, enseguida llama la atención su característica proa de rompehielos (que se quiebra por el peso o desplazamiento del barco), estando hecha la obra viva de su casco de un acero especial de alta resiliencia (elasticidad a bajas temperaturas). Carece además de apéndices y posee una barquilla que protege con una plancha de titanio todos los transductores de las ecosondas. Dispone también de una hélice transversal para mover la proa («bow thruster»), y posee las siguientes características que le permiten que el Lloyds le haya concedido la clasificación "Ice Class 100A IC»: En la parte de popa tiene unas aletas deflectoras del hielo para protección de la hélice, un solo eje (menos vulnerabilidad de las palas de la hélice al estar más próximas a la crujía), propulsión eléctrica de gran potencia, hélice y ancla de respeto, dos tomas de aspiración para el agua de mar de refrigeración (con posibilidad de inyectar agua caliente en los conductos para fundir el hielo que pueda haberse aspirado), aislamiento térmico del casco y mamparos, calefacción, aceite hidráulico especial para bajas temperaturas, duplicidad de todos los sistemas vitales (radares, equipos de navegación, ..), trajes y botes de supervivencia en aguas frías, etc, etc..

A pesar de tener un solo eje, el barco está dotado de gran maniobrabilidad gracias al sistema Schilling-Vectwin que, por medio de 
dos palas o timones independientes, controlados por un ordenador y un «joystick», permiten dirigir el chorro de expulsión de la hélice en los $360^{\circ}$, lo que capacita al buque para mover la popa en cualquier dirección, incluso ir atrás dando avante con la hélice cuando se sitúan ambas palas perpendiculares al eje de la hélice. Existen 5 puestos para control y posicionamiento del buque (puente, alerones de babor y estribor, central de máquinas y central de maniobra).

Posee un Sistema de navegación integrado KONMAP, un radar de banda S (DECCA) con consola ARPA y dos radares de banda X (DECCA y KODEN), sistemas de navegación por satélite diferencial DGPS (Seastar y Trimble), un sondador SIMRAD EM-200, un sonar de hielos SIMRAD, una unidad de referencia vertical (necesaria para las ecosondas multihaz), varios radiogoniómetros (localizadores de emisores) para $\mathrm{MF}, \mathrm{HF}$ y $\mathrm{VHF}$, 2 giroscópicas SPERRY, un receptor fax meteorológico, un sistema de comunicaciones por Satélite Inmarsat-B (teléfono, fax, télex , transmisión de datos), y un receptor de imágenes por satélite de alta resolución TERASCAN.

En cuanto a su sistema de energía y propulsión, el Hespérides tiene una configuración de central eléctrica (AEG Ibérica) con 4 grupos diesel alternadores $(2 \times 1.300 \mathrm{Kw} / 660 \mathrm{v} / 50 \mathrm{hz}$, y 2 × $650 \mathrm{Kw} / 660$ v. / 50 hz.) y cuenta además con 1 grupo de emergencia de $120 \mathrm{kw}$. Su planta propulsora diesel-eléctrica le permite una gran potencia (necesaria para su función de rompehielos) con un bajo nivel de ruidos (necesario para no interferir los equipos acústicos), regulación fina de la velocidad para trabajos científicos y una gran flexibilidad de empleo, sin deteriorarse por efectuar trabajos a velocidades bajas o encontrarse parado en estación durante períodos prolongados de tiempo. La hélice, de cinco palas y 3 mts de diámetro, es movida por dos motores eléctricos principales (MEP) de corriente continua, montados en tándem, de $1.400 \mathrm{Kw}$ de potencia cada uno a $220 \mathrm{rpm}$, directamente acoplados a la línea de ejes.

El sistema de estabilización antibalance es de tanque pasivo por carena líquida (en la época de construcción del Hespérides aún no estaban desarrolladas las aletas estabilizadoras retráctiles para poder navegar entre hielos).

La planta de tratamiento de residuos está compuesta por: sistema de vacío para aguas negras (con tratamiento físico-químico), separador de agua y sustancias oleosas de sentinas, incineradora, compactadora/trituradora de basuras, tanque de almacenamiento de lodos y aceites, y un tanque de tratamiento para «aguas grises» de la cocina.

Está equipado con medios de lucha contra la contaminación marina por posibles derrames de combustible, y con una instalación de detección y lucha contraincendios. 
El agua dulce es producida por medio de 2 potabilizadoras de ósmosis inversa. Los elementos móviles de potencia (chigres, cabestrantes, grúas y pórticos) se accionan por medio de 2 plantas hidráulicas; y dispone también de 2 compresores de aire (para las campañas de sísmica pueden llevarse otros dos en contenedores colocados en la cubierta principal).

Los elementos más importantes para la maniobra y medios de apoyo logístico son: 3 pórticos para arriado e izado de equipos científicos (uno grande en popa y dos en la banda de estribor, ya que todas las descargas líquidas del barco se hacen por la banda de babor y así se evita el riesgo de contaminar las muestras), 5 chigres científicos con un puesto de control automático en la central de maniobra y repetidores en puente y laboratorio, un sistema de cámaras de televisión para vigilancia de la maniobra, 2 grúas (una a proa y otra a popa) que sirven a 2 pañoles de oceanografía, carga y almacenaje de material de transporte, 3 embarcaciones neumáticas ZODIAC MK-V para apoyo logístico y transporte de personal, $1 \mathrm{em}$ barcación semirrígida DUARRY hidrográfica, 2 botes de salvamento polares autónomos de 40 plazas cada uno tipo BSC-40M, 8 balsas de salvamento DUARRY de 25 plazas cada una, 1 embarcación neumática con pescante FERRI de arriado rápido para recogida de hombre al agua (en la Antártida hay que recoger al náufrago antes de tres minutos o fallecerá por hipotermia).

La cubierta está preparada para toma de helicópteros (importantísimo para la posible evacuación o transporte de accidentados o enfermos), con sistemas de ayuda a la navegación, luces especiales, y toma de combustible JP5, y un hangar telescópico.

El buque dispone de una Enfermería altamente equipada, con baño para tratamiento hipotérmico.

Cuenta asimismo con una cámara de tratamiento hiperbárico múltiple, que junto con un equipamiento especial permite efectuar operaciones de buceo en aguas polares con las máximas garantías. El personal embarcado tiene asignado un vestuario especial polar, con 90 trajes especiales para supervivencia en aguas frías.

Un barco excepcional como es el Hespérides tiene también algunas instalaciones poco frecuentes en otros buques, como son: sala de conferencias, biblioteca, peluquería, gimnasio, y sauna finlandesa.

Tiene capacidad para proporcionar alojamiento y comida para 94 personas (57 miembros de la dotación de la Armada, y hasta 30 científicos y técnicos civiles que cambian en cada campaña científica, más una reserva de 7 plazas). 
El «Hésperides» y la aportación de la Armada...

Cuenta con un nivel de repuestos y pertrechos que permite que los mantenimientos sean efectuados por la dotación, y lograr una autonomía de 9 meses fuera de la base.

Resumiendo, el Hespérides dispone de todos los servicios que pudiera tener una pequeña ciudad que previese vivir aislada durante períodos de varios meses y que, además, tuviese que aprovisionar y apoyar logísticamente en todo a otros dos núcleos de población de unas 15 personas durante tres meses (nuestras Bases Antárticas), e incluso apoyar logísticamente a la ya citada Base Antártica Búlgara San Clemente de Orhida, en Isla Livingston.

\section{Equipamiento científico}

El Hespérides, está especialmente preparado para realizar trabajos de geología, geofísica marina, oceanografía física y química, y biología marina. Las unidades de control, análisis y registro de datos se hallan repartidas en trece laboratorios con una superficie total de $380 \mathrm{~m}^{2}$, destacando la existencia de un «laboratorio frío» (se puede regular hasta $-20^{\circ} \mathrm{C}$ y permite simular las condiciones de la Antártida) y de un laboratorio para empleo de isótopos radiactivos (como trazadores de procesos biológicos).

Algunas unidades de medición, toma de datos y muestras, están situadas en el casco del buque (sistema de sondas y correntímetro doppler); no obstante, la mayoría son arriadas desde cubierta, con el buque parado en estación o bien remolcadas con el buque navegando.

Existe a bordo una red informática tipo ETHERNET con 80 puestos de trabajo. A través del Sistema de Adquisición de Datos Oceanográficos (SADO) se adquieren, distribuyen y almacenan todos los parámetros que son obtenidos de forma continua con el termosalinógrafo, la estación meteorológica y el sistema de navegación.

\section{La Política Marítima Nacional}

En las sociedades más avanzadas de este inicio de siglo, la ciencia y la tecnología, junto a la capacidad de innovación, constituyen los elementos básicos para el progreso de las naciones y para atender las demandas sociales, económicas y culturales de sus ciudadanos. La condición de España como nación marítima es una palpable realidad derivada de la geografía, la historia, su cultura milenaria vinculada al Mediterráneo y al Atlántico, el asentamiento de la mayor parte de la población en las zonas costeras, el gran peso económico del insustituible transporte marítimo, la importancia económica de la pesca, el 
creciente desarrollo de la acuicultura, la creciente demanda del sector turismo, la creación de infraestructuras relacionadas con el ocio y los deportes náuticos, etc. etc. Todo ello debería llevar a una política marítima nacional que primara y concediera gran importancia a los aspectos marítimos enunciados, y que afectan a instituciones y agentes de muy diversa naturaleza, tanto pública como privada. ¿Es realmente consciente la nación española de su carácter marítimo y de las ventajas y riesgos que conlleva?

De lo expuesto se deduce que el mayor reto a que nos enfrentamos es un problema de concienciación de la sociedad y de colaboración, cooperación y coordinación de muy diversas instituciones y organizaciones del Estado, de las comunidades autónomas, de la administración local y de las propias empresas, para lograr la integración y aprovechamiento de los recursos disponibles de una forma eficiente y eficaz y lograr una investigación científica de calidad en ciencias y tecnologías marinas, que asegure el desarrollo sostenido de generación de conocimientos que incrementen el bienestar social y cultural de los ciudadanos y que mejore la competitividad de nuestras empresas a través de la innovación tecnológica. Por ello, el Plan Nacional para 2000-2003 se denomina de «Investigación Científica, Desarrollo e Innovación Tecnológica», enfocado, en lo que atañe a la política marítima, a la gestión y sostenimiento de los ecosistemas marinos para conservar su uso futuro.

¿Cómo contribuye la Armada a este Plan Nacional?

En primer lugar, apoyando logísticamente al Hespérides para posibilitar su extraordinaria operatividad, y, lo más importante, proporcionando una dotación de 57 profesionales embarcados, que tiene que detraer de sus escasos recursos de personal, dándole prioridad sobre otras unidades. Asimismo, ha supuesto un notable esfuerzo la reactivación del buque Las Palmas, que vuelve a prestar apoyo logístico a las Bases Antárticas desde el año 2000. Su contribución a la ciencia también la realiza la Armada a través del Instituto Hidrográfico de la Marina (IHM) y del Real Instituto y Observatorio de la Armada (ROA), que cada vez se integran y colaboran más en campañas científicas con diversos grupos de investigación españoles y extranjeros. Pero, sin duda, la mayor contribución directa a la ciencia y a la sociedad española lo hace por medio de las campañas en la Zona Económica Exclusiva Española (ZEEE), de las que ahora hablaremos con más detalle.

\section{Contribución de las Campañas ZEEE a la Política Marítima Nacional}

Por acuerdo del Consejo de Ministros, de fecha 23 de abril de 1993, se dispuso que el BIO Hespérides fuese utilizado durante un 
mes al año como plataforma de investigación para fines relacionados con la Defensa Nacional. En mayo y septiembre de ese mismo año se promulgan dos órdenes ministeriales, estableciendo el Plan de Investigación Hidrográfica y Oceanográfica de la ZEEE, que es incluido en 1994 como un anexo al Plan Cartográfico de las Fuerzas Armadas.

Este «Plan ZEEE» da prioridad a la obtención de datos batimétricos, que se realiza por medio de los sondadores multihaz que van cubriendo de modo continuo un ancho de barrido de tres a siete veces el valor de la profundidad, lo que permite adquirir datos para la elaboración de la cartografía de grandes zonas marítimas en un período de tiempo relativamente corto.

En las campañas de los años 1995, 96 y 97, los levantamientos se efectuaron en las islas Baleares. Las campañas de 1998, 1999 y 2000 se efectuaron en las islas Canarias, a solicitud y por convenio entre el Gobierno de la Comunidad Autónoma de Canarias y el Ministerio de Defensa, completándose la parte más importante del área marítima alrededor del archipiélago, que engloba su plataforma insular y las zonas más significativas e interesantes desde el punto de vista de la morfología. La campaña ZEEE-2001 se efectuó en aguas de Galicia.

Aunque la hidrografía es prioritaria, el magnífico equipamiento científico multidisciplinar del Hespérides permite cubrir simultáneamente otros importantes objetivos en el campo de la oceanografía, geofísica y geología marina, efectuándose la medición de parámetros relativos a la constitución de los sedimentos superficiales, geomagnetismo y gravimetría (permite hacer inferencia acerca de la estructura geológica del subsuelo marino), masas de agua, perfiles de temperatura y velocidad del sonido en función de la profundidad, y medición contínua de la temperatura, salinidad, fluorescencia o toma de muestras de agua del mar a cinco metros de profundidad. Es decir, el Hespérides lleva a cabo un registro contínuo de múltiples datos, sin necesidad de variar su velocidad o tener que pararse en estación mientras recorre las líneas de sonda.

Son responsables del cumplimiento de los objetivos propuestos: el IHM en cuanto a la adquisición y procesado de los datos necesarios para la producción de cartas náuticas y de la información hidrográfica y oceanográfica de interés para la Defensa; y el IEO en lo que se refiere al conocimiento de las características geológicas, geofísicas y morfológicas del fondo oceánico, las características físicas y químicas de las aguas suprayacentes, así como la exploración y posible explotación de los recursos biológicos marinos.

Las campañas ZEEE son un ejemplo de la sinergia que se produce entre distintos organismos en la aproximación multidisciplinar para 
la investigación en ciencias del mar. Así, el IHM es responsable de la batimetría e hidrografía, el IEO de la morfología y sedimentos del lecho marino, la Universidad Complutense de Madrid (UCM) de los estudios gravimétricos, y el ROA del geomagnetismo. Además, en estas campañas ZEEE suelen también embarcar investigadores y becarios de la Universidad de Las Palmas, Universidad de Cádiz, y del Instituto Tecnológico y Geominero de España (ITGE).

Estas campañas ZEEE del Hespérides proporcionan una información esencial sobre las características geográficas, geológicas y geofísicas del fondo marino, de las corrientes y mareas, y de algunas de las características físicas del mar suprayacente, básicas para cualquier estudio de ciencias del mar, y para la infraestructura del transporte marítimo, favoreciendo así la seguridad, eficacia y economía de la navegación como ayuda a la salvaguarda de la vida humana y las propiedades marítimas. Facilitan la protección y gestión del medio ambiente, fomentan el desarrollo sostenido y sostenible de las zonas marítimas españolas, y prestan su apoyo a las distintas administraciones y organismos nacionales, así como a la actividad e industria pesquera.

La necesidad de disponer de esta información, que hemos calificado como esencial y básica, es lo que llevó a la creación en distintos países de los Servicios Hidrográficos Nacionales, que en el caso de España corresponde a nuestro IHM, institución ya bicentenaria. El Hespérides ha supuesto un gran salto cualitativo en la investigación al disponer de tecnología marina de última generación, lo que le permite obtener y procesar datos hidrográficos y oceanográficos de gran calidad y precisión, básicos para cualquier estudio o campaña científica de las múltiples que forman las distintas ramas del árbol de la ciencia del mar.

El transporte marítimo es la red internacional con mayor peso económico, mayor volumen de carga y también el más vulnerable, pues el 80 por 100 de todo el comercio exterior mundial se efectúa por vía marítima. De hecho, la protección de las líneas de comunicación marítimas constituye una de las principales misiones de cualquier marina de guerra, y el dimensionamiento del número de escoltas y buques de guerra de minas necesarios se hace en función de este cometido prioritario. En tiempo de paz, el requerimiento básico del tráfico marítimo es disponer de una cartografía fiable, precisa, adecuada y actualizada con cartas náuticas modernas (electrónicas o digitalizadas), derroteros, libros de faros, anuarios de mareas, etc.,que permitan una navegación segura y la elección de las rutas más rentables. No hay que olvidar que la falta de información precisa obliga a los grandes buques a elegir derrotas más largas y a evitar entrar en puertos cuyos 
El «Hésperides» y la aportación de la Armada...

accesos son dudosos. Tanto es así que el Convenio para la Seguridad en la Mar considera que un buque no está listo para navegar si no dispone de cartas náuticas actualizadas para su derrota prevista y zonas de recalada, $\mathrm{y}$ de portulanos de los posibles puertos y fondeaderos de arribada.

La información obtenida en las campañas ZEEE es necesaria para la administración de la zona marítimo-costera, para el mantenimiento, dragado, limpieza y desarrollo de los puertos (diques de abrigo, varaderos, espigones, etc..), el control de la erosión de la zona marítimo-terrestre, la delimitación de áreas para deportes náuticos y ocio marítimo, el turismo (calidad de los servicios, de las aguas y playas) la ubicación de zonas adecuadas para depuradoras y canalización de aguas residuales, plantas desalinizadoras, vertederos industriales, vertederos de explosivos, zonas permanentes de ejercicios para submarinos, piscifactorías, cetáreas, bateas para mejillones, jaulas de engorde de peces, granjas de acuicultura, arrecifes artificiales para las reservas de pesca, zonas de extracción de depósitos minerales, movimientos de arena, arrecifes de protección de playas, infraestructuras portuarias, instalaciones en alta mar (plataformas, islas artificiales), tendido de tuberías y cables submarinos, etc. etc.

Las campañas ZEEE son también fundamentales para el estudio de la exploración y explotación de los recursos marinos renovables y no renovables. Aquí conviene recordar que el Convenio de Naciones Unidas sobre la Ley del Mar (UNCLOS), que entró en vigor en 1994, determina que las naciones tienen un plazo de 10 años para presentar sus reclamaciones para extender el limite de sus Zonas Económicas Exclusivas más allá de las 200 millas náuticas, hasta un máximo de 350 millas. Estas reclamaciones han de estar basadas en la batimetría (situación del veril de los 2.500 metros de profundidad), la forma y cambio de pendiente del margen continental y en las características geológicas del lecho marino (presencia de sedimentos). Los Servicios Hidrográficos Nacionales (en nuestro caso el IHM) son los únicos organismos competentes para proporcionar la información para documentar dicha reclamación, que tiene que presentar y negociar nuestro MAE para el trazado de los límites de nuestra ZEEE. Probablemente, la única zona susceptible de reunir las condiciones citadas anteriormente, y que no está sujeta a litigio con nuestros países vecinos, sea la parte occidental de la ZEEE de Galicia, por lo que no es de extrañar que la última campaña de la ZEEE (2001) haya tenido lugar en las citadas aguas atlánticas.

Las campañas ZEEE son de interés para la Defensa Nacional porque la Armada es un usuario muy importante de los datos hidrográficos obtenidos para la selección de las derrotas y canales a seguir por el 


\section{Carlos Cordón Scharfhausen}

tráfico marítimo en tiempo de guerra o amenaza de minas, playas aptas para los desembarcos anfibios y cartas náuticas de precisión y especiales para submarinos. En general, para cualquier operación aeronaval, es necesario disponer de datos oceanográficos, hidrográficos y de acústica submarina actualizados y precisos que posibiliten el planeamiento de misiones y tener información de aquellos factores ambientales que pueden incidir en la eficacia de armas y sensores, sobre todo en vista del actual giro estratégico hacia las denominadas «operaciones marítimas de litoral». Este nuevo escenario estratégico marítimo litoral, que contempla la respuesta inmediata a situaciones de crisis, operaciones para la implementación de la paz y operaciones de ayuda humanitaria, ha llevado a la OTAN a la creación de una organización de Evaluación Ambiental Rápida (REA-Rapid Environmental Assessement).

No es de extrañar, pues, que la Armada tenga un firme compromiso en mantener una posición de liderazgo en hidrografía y oceanografía que le permita afrontar con éxito las operaciones marítimas y aeronavales del futuro, y para ello tiende a buscar y fomentar la colaboración y cooperación con la comunidad científica española y europea, con las Universidades, OPIs, e incluso con las empresas. En este sentido, el Hespérides proporciona un claro ejemplo de fructífera simbiosis, del que hay que extraer enseñanzas para un futuro más ambicioso.

\section{Las ventajas del Hespérides como buque de la Armada}

Como buque de la Armada, tiene la consideración legal de parte integrante del territorio nacional, y por tanto goza del principio de inmunidad soberana, aplicable a los requisitos y exigencias derivados de todos los convenios internacionales ratificados por España. Bien es verdad que el Hespérides cumple con todos estos convenios por voluntad de la Administración española, pero nunca se le podrían exigir presuntas responsabilidades por supuesto incumplimiento.

En su propia consideración de buque de la Armada, goza de una representación institucional ante los demás países, que difícilmente podría ostentar si perteneciese a un instituto u organismo civil. De aquí que el Hespérides también lleve a cabo labores de representación en las relaciones internacionales, lo que denominamos «mostrar el pabellón». En cierto aspecto es semejante a nuestro Buque Escuela de Guardiamarinas Juan Sebastián de Elcano, asignándole carácter de cuasiembajada flotante española, especialmente en escalas en el ex- 
El «Hésperides» y la aportación de la Armada...

tranjero y encuentros internacionales con ocasión de Exposiciones Universales o Científicas.

Las campañas de investigación del Hespérides han contado siempre con una amplia cobertura en los medios de comunicación social, quizá atraídos inicialmente por el exotismo de las navegaciones antárticas, pero que ha conducido a que este buque sea conocido en casi toda España. Las ruedas de prensa, entrevistas y reportajes sobre las distintas campañas, han llegado a provocar un constante seguimiento de los medios de comunicación social y de la opinión pública sobre las actividades científicas del Hespérides. La excelente idea de abrir, a partir de 1998, una página web en las campañas antárticas ha aumentado extraordinariamente el grado de conocimiento del Hespérides y de sus trabajos entre la sociedad española, que no hay que olvidar es la que, a fin de cuentas, financia y se beneficia de sus resultados. Por tanto, el Hespérides contribuye a la divulgación y difusión cultural de la ciencia a nivel del hombre de la calle, aumentando la percepción social de la importancia de la investigación oceanográfica, haciendo partícipe a la sociedad española de los logros científicos alcanzados, de la importancia de los océanos y mares, y por ende, de la condición marítima de España.

Las actividades llevadas a cabo por el Hespérides en el extranjero son muy importantes para difundir el nivel tecnológico español, la calidad de nuestra I+D+I y de nuestros investigadores, y a la vez, demostrar que se cumplen los compromisos adquiridos en los tratados internacionales, como el Tratado Antártico y el Protocolo de Madrid.

El Hespérides está apoyado logística y organizativamente por una institución como la Armada, que cubre todo el espacio marítimo de interés nacional con sus Arsenales, Bases, Comandancias y Ayudantías Navales, e incluso cuenta con el apoyo, en el extranjero, de las Agregadurías de Defensa y Navales, lo que posibilita su carácter de buque oceanográfico estratégico.

La Armada aporta una dotación altamente cualificada y es la responsable del mantenimiento y del alistamiento operativo del buque para las campañas científicas. Hasta la fecha, el Hespérides ha efectuado más de 75 campañas científicas, en las que han participando cerca de 2.000 científicos e investigadores, con los apoyos y servicios prestados a bordo durante las 24 horas del día para cada una de las campañas. Si el Hespérides no dependiese orgánicamente de la Armada, y dada su elevada programación de actividades científicas -con una media anual de 255 días de mar y 10 meses fuera de su base, incluídas las Navidades-, necesitaría un mínimo de dos tripulaciones para alternarse, 
que tendrían que percibir elevados emolumentos para retribuir tan alta actividad en zonas tan alejadas de España y que estarían sujetas a las limitaciones derivadas de los correspondientes convenios laborales. La dotación de la Armada, con su esfuerzo y entusiasmo, proporciona todos los servicios y apoyos necesarios para posibilitar la investigación científica oceanográfica a bordo y el apoyo logístico a nuestras Bases Antárticas, habiendo conseguido rentabilizar la utilización del barco al máximo, con una dotación relativamente reducida pero consciente de que su misión es apoyar y colaborar con los científicos embarcados para lograr unos resultados de calidad que contribuyan al prestigio internacional de la ciencia española.

Otro aspecto importante a considerar es que en casi todos los países iberoamericanos, la investigación oceanográfica en general y la antártica en particular es llevada a cabo por las Armadas o Marinas de Guerra, dados los importantísimos intereses estratégicos en juego en la región; por tanto, que el "Hespérides» sea un buque de la Armada permite facilitar enormemente las relaciones institucionales internacionales, de intercambio, y de colaboración, así como los necesarios apoyos logísticos en la mar y en las bases.

Además, el IHM y el ROA son organismos de la Armada con larga tradición científica y reconocido prestigio internacional, y ambos organismos, en estrecha colaboración con el IEO, como hemos visto, se coordinan y participan activamente en las campañas de investigación de la ZEEE. Estas campañas han favorecido también los contactos y colaboraciones del IHM y ROA con las más diversas Universidades.

Queda para el final una faceta muy relevante que proporciona al Hespérides una marcada singularidad y excepcionalidad. Es el único buque de investigación oceanográfica abierto a la participación de cualquier científico o investigador español, o de la Unión Europea; participación que se hace en base exclusivamente al mérito científico de los proyectos de investigación propuestos y su adecuación a las prioridades marcadas en el Plan Nacional de I+D+I. Y precisamente por tratarse de un buque de la Armada queda asegurada esta apertura real a la comunidad científica, actuando como catalizador e impulsor de un "trabajo en equipo», que difícilmente podría conseguirse de otra forma y que hasta la fecha ha dado excelentes resultados. La participación total de investigadores embarcados en todas las campañas puede resumirse así: un 35\% han sido del CSIC, el 34\% de las Universidades, el $16 \%$ extranjeros, el $10 \%$ del IEO y el 5\% de la Armada. Para mantener y potenciar esta «accesibilidad y disponibilidad», desde el año 1998 el Hespérides está efectuando cometidos de buque-escuela, 
El «Hésperides» y la aportación de la Armada...

embarcando profesores y alumnos de las facultades de Ciencias del Mar, aprovechando los tránsitos entre campañas.

La gran capacidad científica multidisciplinar del Hespérides excede a la de cualquier grupo de investigación español, lo que exige la colaboración de distintos grupos a bordo (físicos, químicos, geólogos...), acentuando el carácter multidisciplinar de la investigación oceanográfica y produciendo un efecto sinérgico de cooperación, colaboración y cohesión de los distintos grupos científicos españoles, y de éstos con los de la Unión Europea.

En resumen, y como establece el Plan Nacional de I+D+I 2.000-2.003, el Hespérides, buque de la Armada, gran instalación científico-técnica española, desempeña un cuádruple papel: Favorece la $\mathrm{I}+\mathrm{D}+\mathrm{I}$ en CYTMAR, cataliza la innovación y desarrollo tecnológico en las áreas relacionadas con el diseño y construcción de buques de investigación oceanográfica y su equipamiento, impulsa la colaboración internacional, y refuerza la cohesión científica y tecnológica española. 